OPEN ACCESS

Edited by: Nabil Ahmed,

Baylor College of Medicine, United States

Reviewed by:

Nirali Shah,

National Institutes of Health (NIH),

United States

Christopher Jordan Gamper, Johns Hopkins University, United States

*Correspondence:

Daniel J. Powell Jr.

poda@pennmedicine.upenn.edu

Specialty section:

This article was submitted to

Pediatric Oncology,

a section of the journal

Frontiers in Oncology

Received: 02 November 2018

Accepted: 01 March 2019

Published: 26 March 2019

Citation:

Minutolo NG, Hollander EE and Powell

DJ Jr (2019) The Emergence of

Universal Immune Receptor T Cell

Therapy for Cancer.

Front. Oncol. 9:176.

doi: 10.3389/fonc.2019.00176

\section{The Emergence of Universal Immune Receptor T Cell Therapy for Cancer}

\author{
Nicholas G. Minutolo ${ }^{1,2,3,4}$, Erin E. Hollander ${ }^{1,4,5}$ and Daniel J. Powell Jr. ${ }^{1,4 *}$ \\ 1 Department of Pathology and Laboratory Medicine, Abramson Cancer Center, Perelman School of Medicine, University of \\ Pennsylvania, Philadelphia, PA, United States, ${ }^{2}$ Department of Systems Pharmacology and Translational Therapeutics, \\ University of Pennsylvania School of Medicine, Philadelphia, PA, United States, ${ }^{3}$ Pharmacology Graduate Group, University \\ of Pennsylvania, Philadelphia, PA, United States, ${ }^{4}$ Center for Cellular Immunotherapies, University of Pennsylvania School of \\ Medicine, Philadelphia, PA, United States, ${ }^{5}$ Department of Cancer Biology, University of Pennsylvania School of Medicine, \\ Philadelphia, PA, United States
}

Chimeric antigen receptor (CAR) T cells have shown great success in the treatment of CD19+ hematological malignancies, leading to their recent approval by the FDA as a new cancer treatment modality. However, their broad use is limited since a CAR targets a single tumor associated antigen (TAA), which is not effective against tumors with heterogeneous TAA expression or emerging antigen loss variants. Further, stably engineered CAR T cells can continually and uncontrollably proliferate and activate in response to antigen, potentially causing fatal on-target off-tumor toxicity, cytokine release syndrome, or neurotoxicity without a method of control or elimination. To address these issues, our lab and others have developed various universal immune receptors (UIRs) that allow for targeting of multiple TAAs by $T$ cells expressing a single receptor. UIRs function through the binding of an extracellular adapter domain which acts as a bridge between intracellular T cell signaling domains and a soluble tumor antigen targeting ligand (TL). The dissociation of TAA targeting and T cell signaling confers many advantages over standard CAR therapy, such as dose control of $T$ cell effector function, the ability to simultaneously or sequentially target multiple TAAs, and control of immunologic synapse geometry. There are currently four unique UIR platform types: ADCC-mediating Fc-binding immune receptors, bispecific protein engaging immune receptors, natural binding partner immune receptors, and anti-tag CARs. These UIRs all allow for potential benefits over standard CARs, but also bring unique engineering challenges that will have to be addressed to achieve maximal efficacy and safety in the clinic. Still, UIRs present an exciting new avenue for adoptive $T$ cell transfer therapies and could lead to their expanded use in areas which current CAR therapies have failed. Here we review the development of each UIR platform and their unique functional benefits, and detail the potential hurdles that may need to be overcome for continued clinical translation.

Keywords: chimeric antigen receptor (CAR), universal immune receptor, switchable CAR, cancer immunotherapy, T cell therapy

\section{CONVENTIONAL CAR T CELL THERAPY: SUCCESS AND CHALLENGES}

Cancer immunotherapy is a rapidly growing field that has recently demonstrated clinical efficacy in the treatment of solid tumors and hematological malignancies (1-4). Numerous clinical approaches have been developed to redirect and/or augment immune function against tumor cells, including monoclonal antibodies, checkpoint inhibitors, bi-specific $\mathrm{T}$ cell engaging antibodies (BiTEs), and 
adoptive cell transfer (ACT). The application of ACT therapy for the treatment of malignant cancers has been expanded by the use of $\mathrm{T}$ lymphocytes engineered to express chimeric antigen receptors (CARs) (5). A CAR is a chimeric fusion protein composed of an extracellular single chain antibody variable fragment $(\mathrm{scFv})$, often derived from a tumor antigen specific antibody, that is genetically fused to intracellular $\mathrm{T}$ cell signaling domains, thereby redirecting $\mathrm{T}$ cell specificity and activation toward an antigen expressed on the surface of cancer cells in an MHC-independent manner. Using optimized gene transfer technologies and advanced cell cultivation methodologies, the gene encoding a CAR construct can be efficiently integrated into the DNA of patients' non-reactive T cells, converting them into cancer antigen-reactive $\mathrm{T}$ cells with therapeutic potential.

Much of the clinical success of CAR $\mathrm{T}$ cell therapy has come in the treatment of CD19-positive $\mathrm{B}$ cell malignancies using CD19-specific CAR T cells (CART19) (6-9). There are currently two FDA approved CART19 products, tisagenlecleucel and axicabtagene ciloleucel. Tisagenlecleucel, developed at the University of Pennsylvania, is composed of an extracellular CD19 targeting scFv (FMC63) fused to CD137 (4-1BB) and CD3z intracellular signaling domains and has been approved for the treatment of relapse/refractory $(\mathrm{r} / \mathrm{r}) \mathrm{B}$ cell acute lymphoblastic leukemia (B-ALL) and diffuse large B-cell lymphoma (DLBCL) $(10-12)$. Axicabtagene ciloleucel makes use of the same CD19specific scFv but contains $\mathrm{CD} 28$ and $\mathrm{CD} 3 \mathrm{z}$ as the intracellular signaling domains and was approved for the treatment of $(\mathrm{r} / \mathrm{r})$ large B cell lymphoma in October of 2017 (13). Based upon the high rates of initial cancer remission and durable responses in many patients receiving CART19 cell therapy, the ACT field has expanded with CAR $\mathrm{T}$ cell therapy now being applied against numerous other $B$ cell-associated antigens with encouraging clinical response data being reported in trials targeting BCMA, CD20, and CD22 (14-16).

In spite of the unprecedented clinical success of CAR T cells in these cancer types, the use of a "living drug" has brought with it new and challenging side effects and toxicities. Upon recognition of the target tumor antigen, CAR $\mathrm{T}$ cell activation and expansion at a tremendous rate can result in cytokine release syndrome (CRS), a common side effect of CAR T cell therapy that is characterized by markedly elevated soluble IL2, IL6, IL10, IFNg, as well as elevated CRP, ferritin and decreased fibrinogen (8). In preclinical models, CAR-associated CRS is linked with myeloid cell release of IL-1 and IL-6, corroborating the current clinical method of CRS control with the use of the anti-IL-6 antibody tocilizumab and offering an option for IL-1 antagonists in the control of CRS $(17,18)$. In addition to CRS, all clinicallyapproved CAR T cell treatments can cause sustained B cell aplasia in patients due to the prolonged persistence and anti-B cell activity of the infused CART19 cells. While B cell aplasia as a toxicity in patients treated with CART19 cells is manageable with intravenous immunoglobulin treatment and antibiotics, severe toxicities and even death has been reported in some trials of CAR-T cell therapy where the target antigen is highly expressed on cancer cells and expressed at lower levels on normal healthy tissues, resulting in on-target, off-tumor toxicities (19-21). Based upon current practices, there are presently no mechanisms in place to quantitatively and temporally control the expansion and activation of CAR $\mathrm{T}$ cells following their administration.

Finally, although nearly $90 \%$ of $\mathrm{r} / \mathrm{r}$ B-ALL patients achieve a complete response 1 month after administration of CART19 cell therapy, a significant number of patients still relapse (22). Only $55 \%$ of the patients that experienced an initial CR are disease-free at 1 year, but relapses are rarely observed after 1 year. Two general mechanisms of relapse occur in these patients. For some patients, relapses are associated with poor $\mathrm{T}$ cell function or persistence $(23,24)$. These are generally $\mathrm{CD} 19+$ relapses where the leukemic blasts maintain surface expression of the CD19 target, and the patient can accordingly be retreated with CART19. In a second set of patients, relapses occur despite a strong initial activity and engraftment of CART19 cells. In these cases, the leukemia recurs with apparent loss of CD19. Three major mechanism of CART19 tumor escape have now emerged. Multiple studies have shown that resistance to CART19 therapy is accompanied by the apparent disappearance of the target CD19 protein as a result of gene splicing, frameshifting or deletion $(25,26)$. In some cases, one of the two gene copies that code for CD19 on chromosome 16 is deleted, and the other copy becomes damaged as a result of mutations in coding areas of the CD19 gene, most frequently in exon 2, which encodes for the epitope recognized by the CD19 CAR. By an alternative mechanism of gene splicing, exons 2,5 , and 6 were frequently skipped in the same patients, making mutations in exon 2 largely irrelevant since the deletion of exons 5 and 6 resulted in premature termination of the CD19 protein and the deletion of exon 2 resulted in the production of a modified version of CD19, which was more stable than its standard version but not recognized by CART19 cells. Other studies have demonstrated lineage switching as another possible mechanism of CART19 resistance $(27,28)$. Gardner et al. reported on two unique CD19negative relapses arising from an ALL to AML lineage switch shortly after CART19 cell therapy in two out of seven treated patients with mixed lineage leukemia (MLL) B-ALL(28). In one rare instance, the CD19 CAR gene was engineered into a single leukemic B-ALL clone (29). Here, the presence of the anti-CD19 $s c F v$ portion of the CAR and its binding to the CD19 molecule on the leukemia cell surface resulted in masked expression of CD19 target, resulting in resistance to CART19 therapy.

Thus, CAR T cell therapy that is designed to target only a single tumor antigen allows tumor cells to escape the therapy through loss of the target antigen or the antigenic epitope, with no simple and efficient method to switch the target antigen without having to make an entirely new CAR. While treatment for CD19-negative relapsed cancer after CART19 therapy may be achieved through subsequent administration of $\mathrm{CD} 123$ or CD22 CAR T cells, this is not without significant financial costs and safety risks $(15,30)$. Alternatively, $\mathrm{T}$ cells engineered for dual antigen specificity (e.g., CD19 and CD123) may mediate more complete remission and overcome these mechanisms of antigen escape (31).

Beyond the CART19 paradigm, the restricted targeting of a single tumor antigen by CAR $\mathrm{T}$ cells appears to be a major limiting factor to successful CAR $\mathrm{T}$ cell treatment of solid tumors. Unlike B-ALL where nearly all cancer cells express 
the CD19 antigen, solid tumors are often comprised of tumor cells with diverse and heterogeneous expression levels of target antigen, rendering them insensitive to CAR $\mathrm{T}$ cell recognition (32). This is evidenced in a trial of intravenous infusion of CAR T cells for recurrent glioblastoma (GBM) where EGFRvIII CAR $T$ cells effectively trafficked to regions of active GBM and expression levels of EGFRvIII in the persisting lesions declined in $71.4 \%(5 / 7)$ of treated patients for whom postinfusion tumor was available (33). Alternative CAR strategies will be necessary to deliver multi-antigen targeting and adapt to the changes that accompany immune pressure against a single antigen.

\section{UNIVERSAL IMMUNE RECEPTORS WITH ADAPTABLE SPECIFICITY}

CARs are architecturally rigid, modular proteins that commonly consist of an extracellular antigen targeting domain, an extracellular spacer region, a transmembrane domain, and one or more intracellular signaling domains. As such, CARs represent a forced, dominant bypass to traditional $\mathrm{T}$ cell receptor (TCR) binding to peptide/MHC complexes for $\mathrm{T}$ cell activation, but akin to the TCR, their specificity is fixed and dictated by the scFv used in the creation of the CAR construct. Thus, once the CAR is engineered into the $\mathrm{T}$ cell, the redirected specificity and activity of the modified $\mathrm{T}$ cell is permanent and not easily adapted or controlled.

In order to overcome this and other limitations of CAR T cell therapy, we and others have developed alternative chimeric receptor designs that rely in part upon the fundamental principles of conventional CAR architecture but provide the means for quantitative and temporal control of CAR $\mathrm{T}$ cell specificity and activity. Termed universal immune receptors (UIRs), these adaptable chimeric proteins maintain a relatively similar structure to CARs but contain an extracellular adapter domain that functions as an orthogonal bridge between intracellular T cell signaling domains and a soluble tumor antigen targeting ligand (TL). Unlike the CAR approach, this strategy allows for selective post-translational redirection of $\mathrm{T}$ cell specificity and function against antigen bearing tumor cells (Figure 1). Accordingly, the split structure design of UIRs has the potential benefit of being able to overcome several limitations of standard CAR therapy; namely, by allowing for dose regulation of effector function, redirection of CAR T cells against multiple target antigens or epitopes, and the ability to use a single chimeric receptor to target multiple tumor types.

Conceptually, all universal immune receptors serve the same basic function: allowing for $\mathrm{T}$ cell activation in response to the binding of an extracellular adapter moiety to a partnering binding domain or "tag" on an antigen-bound TL. An adaptertag binding partnership substitutes for the standard scFvantigen engagement which elicits $\mathrm{T}$ cell activation in CAR $\mathrm{T}$ cells. Though all UIRs fit this basic structural strategy, there are four distinct types of UIRs that have been developed to date: (i) antibody dependent cellular cytotoxicity (ADCC) receptors (34-37), (ii) Bispecific protein mediated linkage (38,
39), (iii) anti-tag CARs (40-51), and (iv) tag-specific interactions (52-54) (Figure 2).

\section{FC-BINDING CHIMERIC IMMUNE RECEPTORS}

UIRs apply many of the basic principles of ADCC to T cell therapy. In ADCC, effector cells that express Fc receptors can actively lyse a target cell, whose membrane-surface antigens have been bound by specific antibodies which serve as an immunological bridge between the Fc receptor and the target antigen. Further, clinical observations from monoclonal antibody trials suggest that ADCC mediated by Fc $\gamma$ RIIIa (CD16)-bearing cells, such as natural killer (NK) cells, is a major mechanism of action.

In 2006, Clemenceau and colleagues reported on an early form of UIR which consisted of an extracellular CD16 domain attached to an intracellular FcIR domain (34). They noted that the gene coding Fc $\gamma$ RIIIa displays a functional allelic dimorphism generating allotypes with either a phenylalanine $(\mathrm{F})$ or a valine (V) residue at amino acid position 158. Since NK cells from donors homozygous for Fc $\gamma$ RIIIa-158V (VV) bind more human IgG1 and IgG3 than do NK cells from donors homozygous for Fc $\gamma$ RIIIa-158F (FF) (55), the use of CD16(VV) as an extracellular adaptor is preferred over CD16(FF) in UIR development as it allows for enhanced binding of human IgG isotypes to the receptor. Clémenceau et al. showed that human $\mathrm{T}$ cells engineered to express the chimeric CD16VV protein retained their natural specificity instilled by their endogenous $\mathrm{T}$ cell receptor, but additionally proliferated, secreted cytokine and specifically killed antigen-positive leukemia cells in vitro upon addition of CD20-specific (rituximab) IgG antibody. Notably, the CD16VV platform made ready use of a clinical-grade antibody without further manipulation and the activation of CD16(VV) UIR $T$ cells was dependent upon antibody immobilization; soluble IgG, as might be found in the circulation, did not activate UIR T cells. This group later demonstrated the capacity of this system to mediate cancer regression in a preclinical model of subcutaneous human HER2+ breast cancer in vivo after intraperitoneal injection of HER2-specific trastuzumab and subsequent administration of CD16(VV)-engineered NK cells, NK-92 CD16 (56). Using a similar platform, Ochi et al. showed redirected $\mathrm{T}$ cell specificity against HER2, CD20 and CCR4 in vitro, and cytotoxic effector functions against Raji lymphoma cells injected into immunodeficient mice (36). With an understanding that incorporation of a costimulatory signaling domain enhances CAR $\mathrm{T}$ cell proliferation, persistence and function (57-61), a CD16(VV) UIR was later developed that contained in tandem $4-1 \mathrm{BB}$ and $\mathrm{CD} 3 \mathrm{z}$ intracellular signaling domains $(4-1 \mathrm{BBz})$, with $4-1 \mathrm{BBz}$ showing the greatest efficacy in vitro (35).

Based upon these and other findings, clinical trials using the CD16VV UIR are currently underway for the treatment of non-Hodgkin's lymphoma (CD20+), HER2-positive cancer (trastuzumab) or multiple myeloma (SEA-BCMA) (Unum: NCT02776813, NCT03189836, NCT03266692, NCT03680560). 


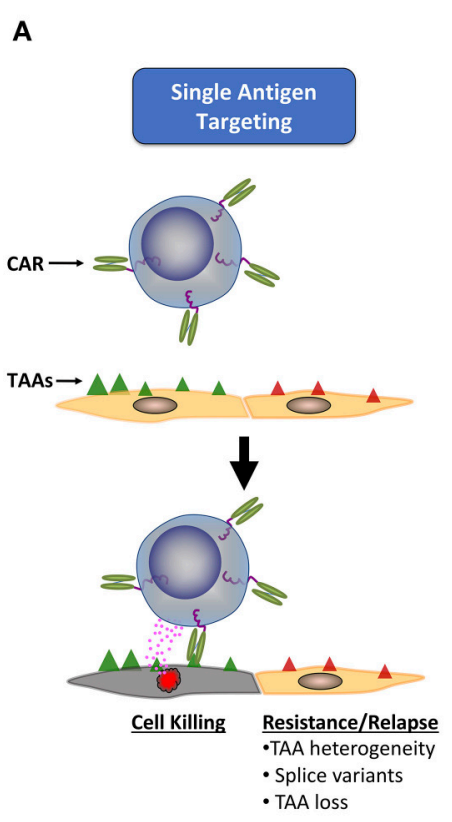

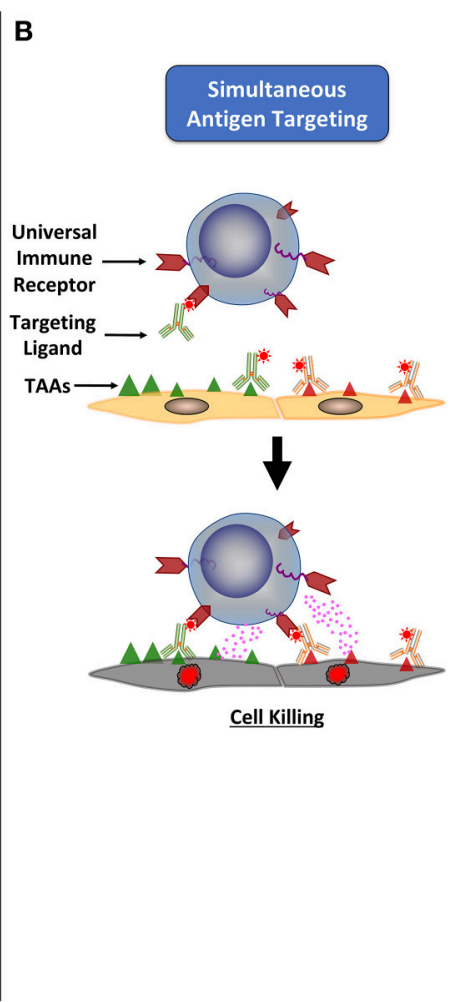

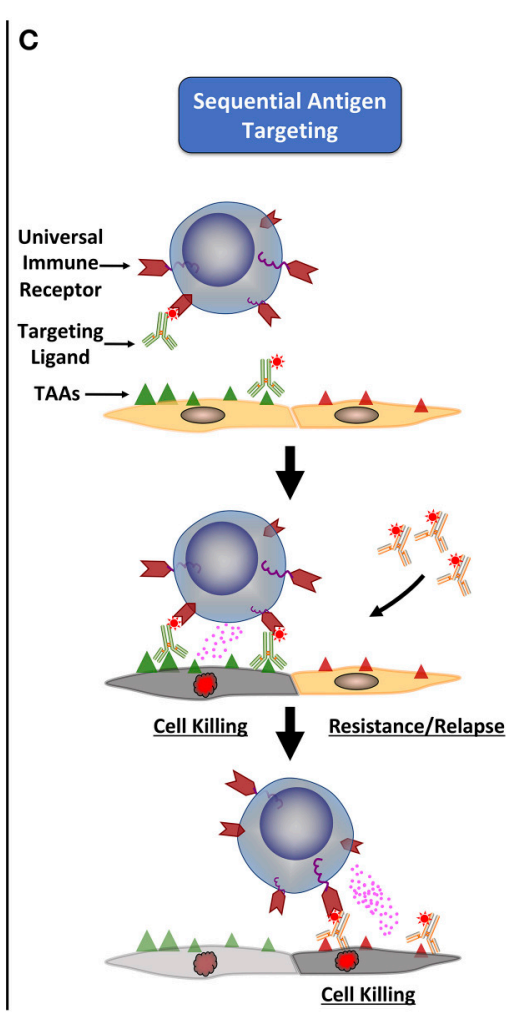

FIGURE 1 | Universal immune receptors have expanded potential to target multiple tumor associated antigens. (A) Classical CAR T cells are only able to target a single tumor associated antigen (TAA), allowing tumor cells to evade detection through loss or down regulation of the targeted TAA, or the expression of TAA splice variants. To combat this, universal immune receptors allow for either simultaneous (B) or sequential (C) addition of ligands targeting multiple TAAs. The simultaneous targeting of multiple TAAs could lower the chance of immune evasion seen with single antigen targeting, while the ability to change the antigen target of choice over time could allow for continual targeting of an evolving tumor antigenic landscape.

Early clinical trial results reported for the CD16(VV) drug, ACTR087 (Unum), at the low dose $\left(0.5 \times 10^{6}\right.$ ACTR T cells $\left./ \mathrm{kg}\right)$ in combination with the anti-CD20 antibody, Rituxan, included two complete responses and one partial response in 6 evaluable patients with Rituxan-resistant NHL; no T cell activation-related adverse events were observed. However, at dose level two (1.5 $\times 10^{6}$ ACTR $\mathrm{T}$ cells $/ \mathrm{kg}$ ) two of the nine treated patients died from serious adverse events that included severe CRS (cytokine release syndrome) and neurotoxicity ${ }^{1}$. Of the two events of CRS, one patient subsequently experienced a fatal case of enterococcal sepsis considered related to ACTR087 and one patient subsequently experienced a fatal case of sepsis considered not related to ACTR087. After a temporary FDA hold, these trials are again open with modified protocols and dosing.

Whether the ability of the CD16VV domain to bind to aggregate or potentially auto-reactive IgGs in the circulation or immobilized in tissues is associated in any way with these toxicities is not known, however, Fc-binding UIRs remain potentially less specific than other UIR model types due to their intrinsic ability to bind host IgGs.

\footnotetext{
${ }^{1}$ https://www.sec.gov/Archives/edgar/data/1622229/000119312518068918/ d416842ds1.htm.
}

\section{THE DEVELOPMENT OF UIRS THAT UTILIZE BISPECIFIC TARGETING LIGANDS}

The following three UIR platforms further enhance the specificity of the receptor for its TL. Bi-specific protein-binding UIRs function through co-engagement of the tumor antigen and the extracellular portion of the UIR through a soluble bispecific bridging protein. This allows for direct incorporation of costimulation into the $\mathrm{T}$ cell response, which is an advantage over current bi-specific $\mathrm{T}$ cell engagers (BiTEs) that only engage $\mathrm{CD} 3 z$ directly. In addition, the ex vivo engineering of bi-specific antibody UIRs provides an opportunity to select and expand the desired subset of $\mathrm{T}$ cells, whereas BiTEs can indiscriminately bind all CD3 expressing T cell, whether proinflammatory or immunosuppressive in function. Urbanska and colleagues developed the first bi-specific antibody UIRs using the extracellular domain of the self-protein, folate receptor $\alpha(\mathrm{FR} \alpha)$ genetically fused to $\mathrm{CD} 28$ and $\mathrm{CD} 3 \mathrm{z}$ intracellular $\mathrm{T}$ cell signaling domains (38). In co-culture experiments, the addition of a novel bispecific antibody targeting $\mathrm{FR} \alpha$ and a tumor antigen-specific antigen (CD20) led to the selective redirection of the UIR $\mathrm{T}$ cells against $\mathrm{CD} 20+$ tumor cells, while untransduced cells remained inactive. Increased secretion of IFNg, TNFa and IL-2 cytokines was dependent upon the 


\begin{tabular}{|c|c|c|c|}
\hline \multicolumn{2}{|c|}{ Tag Specific } & Bispecific & Fc-binding \\
\hline $\begin{array}{l}\text { Natural Binding Partner } \\
\text { Immune Receptor }\end{array}$ & Anti-Tag CAR & $\begin{array}{l}\text { Bispecific Protein } \\
\text { Engaging Immune } \\
\text { Receptor }\end{array}$ & $\begin{array}{l}\text { ADCC-mediating } \\
\text { Immune Receptor }\end{array}$ \\
\hline Tumor cell & Tumor cell & Tumor cell & Tumor cell \\
\hline \multirow[t]{2}{*}{ labeled TL } & labeled TL & BsAb $\longrightarrow$ & IgG1 Ab $\rightarrow$ TAA \\
\hline & $\begin{array}{l}\int \begin{array}{c}\text { Co-Stim } \\
\text { CD3z }\end{array} \\
\text { T cell }\end{array}$ & $\begin{array}{l}\int \begin{array}{c}\text { Co-Stim } \\
\text { CD3z }\end{array} \\
\text { T cell }\end{array}$ & $\begin{array}{l}\int \begin{array}{c}\text { Co-Stim } \\
\text { CD3z }\end{array} \\
\text { T cell }\end{array}$ \\
\hline $2012-2018$ & $2012-2018$ & 2014-2017 & 2006-2018 \\
\hline $\begin{array}{l}\text { Avidin-Biotin: Urbanska et al. } \\
\text { 2012, Lohmueller et al. } 2018\end{array}$ & $\begin{array}{l}\text { FITC: Tamada et al. 2012; Kim } \\
\text { et al. 2015; Ma et al. 2016; } \\
\text { Cao et al. 2016; Chu et al. } \\
2018\end{array}$ & $\begin{array}{l}\text { Folate Receptor } \alpha \text { : Urbanska } \\
\text { et al. } 2014\end{array}$ & $\begin{array}{l}\text { CD16(VV): Clemenceau et al. } \\
\text { 2006; Kudo et al. 2013; Ochi } \\
\text { et al. 2014; D'Aloia et al. } 2016\end{array}$ \\
\hline \multirow[t]{2}{*}{$\begin{array}{l}\text { Leucine Zipper: Cho et al. } \\
2018\end{array}$} & $\begin{array}{l}\text { PNE: Rodgers et al. 2016; Cao } \\
\text { et al. 2016; Raj et al. 2018; } \\
\text { Viaud et al. } 2018\end{array}$ & CART19: Ambrose et al. 2017 & \\
\hline & $\begin{array}{l}\text { La-SS-B: Feldmann et al. 2014; } \\
\text { Bachmann et al. 2014; } \\
\text { Cartellieri et al. 2016; Albert } \\
\text { et al. } 2017\end{array}$ & & \\
\hline
\end{tabular}

FIGURE 2 | Types of universal immune receptor platforms. The bridging of intracellular T cell signaling domains and antigen targeting through an extracellular adaptor moiety is the fundamental design for all current universal immune receptors. Variations to this format have led to the development of four distinct UIR subsets. Tag specific UIRs rely on binding of the extracellular domain to a tag present on the targeting ligand. This can either be done through the use of natural binding partners, such as avidin-biotin or leucine zippers, or through binding of an anti-tag CAR to its cognate antigen tag. Bispecific protein engaging molecules underlie another subset of UIRs, engaging the T cell and tumor simultaneously to stimulate T cell effector function. The final UIR platform functions through a mechanism similar to antibody dependent cellular cytotoxicity (ADCC) by engaging tumor specific antibodies with the extracellular CD16 Fc binding domain.

incorporation of the CD28 signaling domain into the UIR. More recently, Aleta Biotherapeutics (Natick, MA) described a parallel technology that allows CART19 T cells to be redirected against additional tumor antigens through the use of a soluble CD19-antibody fusion protein (39). Here, the CD19 portion of the protein binds to the CART19 receptor while the scFv portion binds to the target antigen, bridging $\mathrm{T}$ cell and tumor cell. This technology takes advantage of the known clinical activity and persistence of CART19 cells in patients, and may provide a clinical tool to address CD19-negative relapse in CART19 recipients by redirecting the CAR $\mathrm{T}$ cells against $\mathrm{CD} 20$, using a CD19-CD20scFv fusion protein. It may also have utility in the treatment of solid tumors, however the potential induction of CRS, neurotoxicity and long term B cell aplasia in these patients remains a risk. This risk is limited in tag-specific UIR approaches in which the UIR uniquely binds to the TL and no other cell surface protein in the body.

\section{TAG- AND ANTI-TAG-SPECIFIC UNIVERSAL IMMUNE RECEPTORS}

Tag-specific UIRs exploit natural ligand-ligand binding system to facilitate receptor-TL interactions. Relying upon the known interaction between biotin and avidin, the first tag-specific UIR to be developed used dimeric chicken avidin for the extracellular domain of the receptor, thereby allowing for redirection of engineered $\mathrm{T}$ cells against biotinylated TLs, including both scFvs and antibodies (52). The biotin binding immune receptor (BBIR)-expressing $\mathrm{T}$ cells exclusively recognized, bound and killed cancer cells pretargeted with antigen-specific biotinylated antibodies, but not non-biotinylated antibodies, in a TL dose dependent manner. The versatility afforded by BBIRs also permitted sequential or simultaneous targeting of a combination of distinct antigens, allowing for tailored antigen specificity in a time and dose dependent manner. Further work on the biotinspecific platform led to the use of a high affinity monomeric 
streptavidin extra cellular domain (53). Cho et al. developed a tag-specific system, termed SUPRA CAR, using synthetic and human derived leucine zipper domains with the unique ability to control effector function through affinity tuning of the UIR-TL interaction (54).

Anti-tag CARs are UIRs that use a standard scFv-based CAR receptor whose cognate antigen is a small peptide or molecule tag. These tags are genetically fused or chemically conjugated to various TL types, ranging from small molecules to antibodies. These tag-labeled TLs serve as a bridge between the anti-tag CAR $\mathrm{T}$ cell and antigen expressing tumor cell, leading to titratable elicitation of effector function. Anti-tag CARs have been designed to bind FITC $(40,43,44,47,50)$, a peptide neo-epitope (PNE) from the yeast transcription factor GCN4 $(45,47,49,51)$, and E5B9 peptide derived from nuclear antigen-La-SS-B (41, 42, 46-48). The inherent flexibility of these tag-based systems may allow for refined engineering of either the receptor or the $\mathrm{TL}$ to optimize $\mathrm{T}$ cell effector function against specific tumor types. Though none of the anti-tag CARs are currently used in the clinic, both Endocyte ${ }^{2}$ (anti-FIT CAR) and Calibr ${ }^{3}$ (antiPNE CAR) are progressing toward clinical trial testing of their respective platforms.

There are many facets of these platforms that will need to be precisely designed in order for their true potential to be reached in the clinic, but the current UIR literature clearly illustrates the significant promise that these receptors hold for clinical use.

\section{ASPECTS OF UNIVERSAL IMMUNE RECEPTOR DESIGN}

Due to the split nature of the receptor and TL, careful consideration needs to be given to the engineering of each member and portion to ensure optimal functionality against targeted tumors. UIR composition will likely be impacted by the same factors that affect standard CAR design, including selection of optimal stimulation and costimulation domains, hinges, transmembrane regions, and targeting domains (5). CAR $\mathrm{T}$ cells typically use scFvs as their standard targeting moiety, though other molecules such as DARPins and cell adhesion proteins have been used as well $(62,63)$. Each of these unique TLs must be engineered with respect to the receptor construct itself. A broader variety of TL molecules have been used to redirect UIR T cells, including antibodies, scFvs, bispecific scFvs, Fab fragments, nanobodies, and small molecules $(43,45,46,52)$. The expanded repertoire of potential TL types brings with it the added ability to alter many properties of the UIR system itself, such as affinity of the receptor for the TL, affinity of the TL for the target antigen, epitope binding valency, pharmacokinetics of effector function, and tumor penetrance and distribution of the TL (48, 54, 64, 65). Tag valency and placement are also key considerations for TL development, with the potential to impact effector function and induce target-independent activation (45, 66). Emerging data suggest that these factors will have a major impact on

\footnotetext{
${ }^{2}$ https://endocyte.com/pipeline/

${ }^{3}$ https://www.scripps.edu/news-and-events/press-room/2018/20180625-calibrabbvie.html
}

the design of optimally functional UIR systems against each target antigen.

\section{CONTROLLING THE IMMUNOLOGIC SYNAPSE}

One key aspect of CAR and BiTE design is the optimization of the immunologic synapse formed between the $\mathrm{T}$ cell and target cell (67). Hinge domains, typically derived from IgG4 or CD8 molecules, serve to extend the scFv farther from the plasma membrane for greater efficiency in ligand binding and tumor lysis (5). The length of the hinge region can have a strong impact on CAR function, with optimal spacer length varying based on the epitope being targeted $(68,69)$. Insertion of a flexible hinge region may also relieve steric inhibition between CAR binding moieties and cancer epitopes, as seen in the improved lysis capabilities of a MUC1-targeted CAR (70). Thus, the extracellular spacer domain in standard CARs likely needs to be optimized for each specific antigen target to allow for maximum CAR $\mathrm{T}$ cell efficacy.

The spatial relationship between a UIR bearing $\mathrm{T}$ cell and a tumor cell can be altered through either the extracellular spacer domain of the receptor, the size of the TL, or the placement of the tag on the TL. Using site-specific tag conjugation and molecular engineering techniques, anti-tag UIR studies show that tag placement on the TL is important for optimizing its efficacy against each target antigen and is impacted by whether the epitope is distal or proximal to the tumor cell membrane $(44,45)$. For instance, one study demonstrated that targeted placement of the tag proximal to the epitope binding site increased the antitumor activity in the targeting of CD19+ tumor cells (45). Additional studies directly compared site-specific tag conjugation to random tag conjugation and noted that random incorporation led to a decrease in efficacy both in vitro and in vivo (44). Taken together, these results demonstrated that tag placement can be optimized independently from the receptor through the use of site-specific tag conjugation of the tag to the TL.

Changing the extracellular spacer of the UIR is another method for synapse space optimization. Using their PNE tag system, Rodgers et al. showed that the use of a short IgG4 hinge region leads to increased efficacy in the targeting of CD19+ cells (45). In additional experiments targeting CD20 and CD22 with UIR T cells, the importance of pairing the correct hinge with tag placement for optimal tumor cell lysis was further demonstrated $(44,45)$. Taken together, these results underscore the need for precise engineering to optimize UIR $\mathrm{T}$ cell activity for a given antigen. Unlike with standard CARs this optimization can be done through alterations to the TL, meaning that a single UIR receptor could still be used to optimally target multiple antigens. Since exogenous development of TLs can be performed independent of manipulation of the receptor itself, this could potentially allow for higher throughput screening and optimization of effector function compared to optimization techniques used for individual CARs. 


\section{TOXICITIES AND METHODS OF REGULATING EFFECTOR CELL FUNCTION}

As mentioned earlier, CAR T cell therapy is not without toxicity. On-target, off-tumor $\mathrm{T}$ cell engagement is a potentially fatal side effect of CAR therapy. This is especially troublesome in the targeting of solid tumors, which often overexpress antigens already present on normal tissue. Targeting of the commonly overexpressed tumor antigen HER2 was fatal in a single patient clinical trial, with complications potentially arising from recognition of low-level HER2 expressed on normal lung cells (20). An early clinical trial for metastatic renal cell carcinoma was forced to cease treatment after four of the eight patients exhibited abnormalities in liver enzymes, likely due to targeting of carbonic anhydrase IX (CAIX) on bile duct epithelial cells by the infused CAIX-specific CAR-T cells (21). Additionally, cytokine release syndrome, caused by robust $\mathrm{T}$ cell activation post-infusion, can cause serious health complications in patients $(71,72)$. Neurological toxicity, including delirium in fevered states and global encephalopathy, has also been reported in relation to CD19-directed CAR T cell therapy and may in part be linked to CRS $(73,74)$. Though CRS is currently managed by infusion of the anti-IL6 antibody tocilizumab, the ability to dose-control CAR T cell effector function could alleviate its need.

Improving the clinical safety of CAR T cells while retaining antitumor function is currently a major area of research. Significant effort is being made to develop effective safety mechanisms to shut off, or otherwise titer, CAR-T cell function in the event of unmanageable toxicity. These "switch" functions use exogenous molecules to induce either the activation or death of CAR-T cells. The first suicide switch system transferred the herpes simplex virus thymidine kinase (HSV-TK) gene into donor $\mathrm{T}$ cells. Upon administration of ganciclovir, the thymidine kinase of HSV-TK catalyzes the transformation of ganciclovir to the lethal triphosphate ganciclovir (GCV) (75). Although found to be safe and efficacious clinically (76), the HSV-TK system has drawbacks in its potential for immunogenicity (77). Another example of an "off-switch" is the inducible Caspase 9 system (iCAsp9) which causes apoptosis in activated T cells upon administration of the small molecule AP1903. Upon treatment, those cells which express the iCasp9 transgene are rapidly and preferentially killed, allowing for cessation of $\mathrm{T}$ cell activity in vivo $(78,79)$. The iCasp9 CART system is currently under clinical investigation, targeting advanced melanoma, neuroblastoma, sarcoma, and other solid tumors which express GD2 (80). The Casp9 gene has also been fused to rapamycin binding domain FKBP12, allowing for use of rapamycin as a kill-switch molecule (81).

ADCC mediated depletion of $\mathrm{T}$ cells is another possible method of elimination. Expression of the EGFR extra cellular domain in $\mathrm{T}$ cells allows for depletion through infusion of cetuximab and has been used in clinical trials testing MUC16 targeting CAR T cells $(82,83)$. A similar methodology was developed by expressing CD20 on T cells, therefore enabling rituximab infusion as a means to deplete engineered $\mathrm{T}$ cells in mouse models (84). This system, named RQR8, is currently being used in clinical trials for non-Hodgkin lymphoma and multiple myeloma (NCT03590574, NCT03287804). A study comparing iCasp9, HSV-TK, and CD20 depletion suicide switches concluded that both the iCasp9 and CD20 allowed for rapid and effective $\mathrm{T}$ cell depletion, albeit iCas9 appeared more efficient (85). Clinical trials have also been conducted using mRNA electroporated CAR T cells, which gradually lose CAR expression over time as the mRNA degrades (86).

As an alternative approach to decrease off-tumor cell killing, antigen-specific inhibitory chimeric antigen receptors (iCARs) have been developed that comprise an extracellular antigenbinding domain and an intracellular CTLA-4 or PD-1 signaling domain. This allows iCAR $\mathrm{T}$ cells to transmit inhibitory signals into the $\mathrm{T}$ cell to suppress the $\mathrm{T}$ cell response only upon binding to a self-antigen expressed on normal cells. In this way, strong therapeutic function may be retained against target tumor cells, which lack the healthy tissue antigen, while any healthy cell carrying the self-antigen would trigger CTLA-4 or PD-1 signaling and be preferentially spared (87). Similar to iCARs, masked CARs (mCARs) remain masked from antigen recognition until a protease which is commonly activated in the tumor microenvironment unmasks the antigen recognition domain of the CAR, thus allowing for localized tumor recognition and activity. As proof of concept, a third generation mCAR specific for EGFR was "masked" using an N-terminal peptide which blocks the antibody binding site of an EGFR-specific CAR (88). Upon exposure to tumor-associated proteases, $\mathrm{N}$-terminal peptide was cleaved and the activity of mCAR $\mathrm{T}$ cells against EGFR enhanced.

Unlike these approaches, UIRs utilize methods of effector function control that do not involve the direct genetic engineering of a "kill-switch" or other genetic modification to the $\mathrm{T}$ cell genome. In order for UIRs to engage antigen expressing tumor cells, TL must be introduced to the system; in the absence of TL the UIR T cells are viable but inactive. This is not the case for suicide switch systems which result in the deletion of the engineered $\mathrm{T}$ cell product and thus a termination of the therapy. UIR T cells persist in the circulation of treated mice following the clearance of tumor and the discontinuation of TL administration $(44,45)$. Accordingly, discontinuation of TL administration can prevent adverse effects associated with the persistent CAR T cell activity while also providing the opportunity for subsequent TL administration upon cancer relapse.

In addition to the benefits of allowing for safe, engineered $\mathrm{T}$ cell persistence, UIR systems provide a mechanism for quantitative control of effector cell function through manipulation of the administered dose or alterations to the dosing schedule (Figure 3). In a manufacturing and infusion approach similar to that used for CAR $\mathrm{T}$ cells, patient $\mathrm{T}$ cells that are ex vivo engineered to express the UIR can be administered prior to, simultaneously with, or after TL dosing. As described below, these TL dosing regimens allow for exquisite control of cytokine secretion and tumor lysis by UIR $\mathrm{T}$ cells in vitro and in vivo, and dose escalation over the course of a treatment can combat relapse in mouse models $(44,45,52,54)$. These aspects of UIRs have significant clinical implications.

Nearly all patients with B-ALL that receive highly active CART19 $\mathrm{T}$ cells experience some level of CRS ranging from mild flu-like to life threatening symptoms (89). Here the 


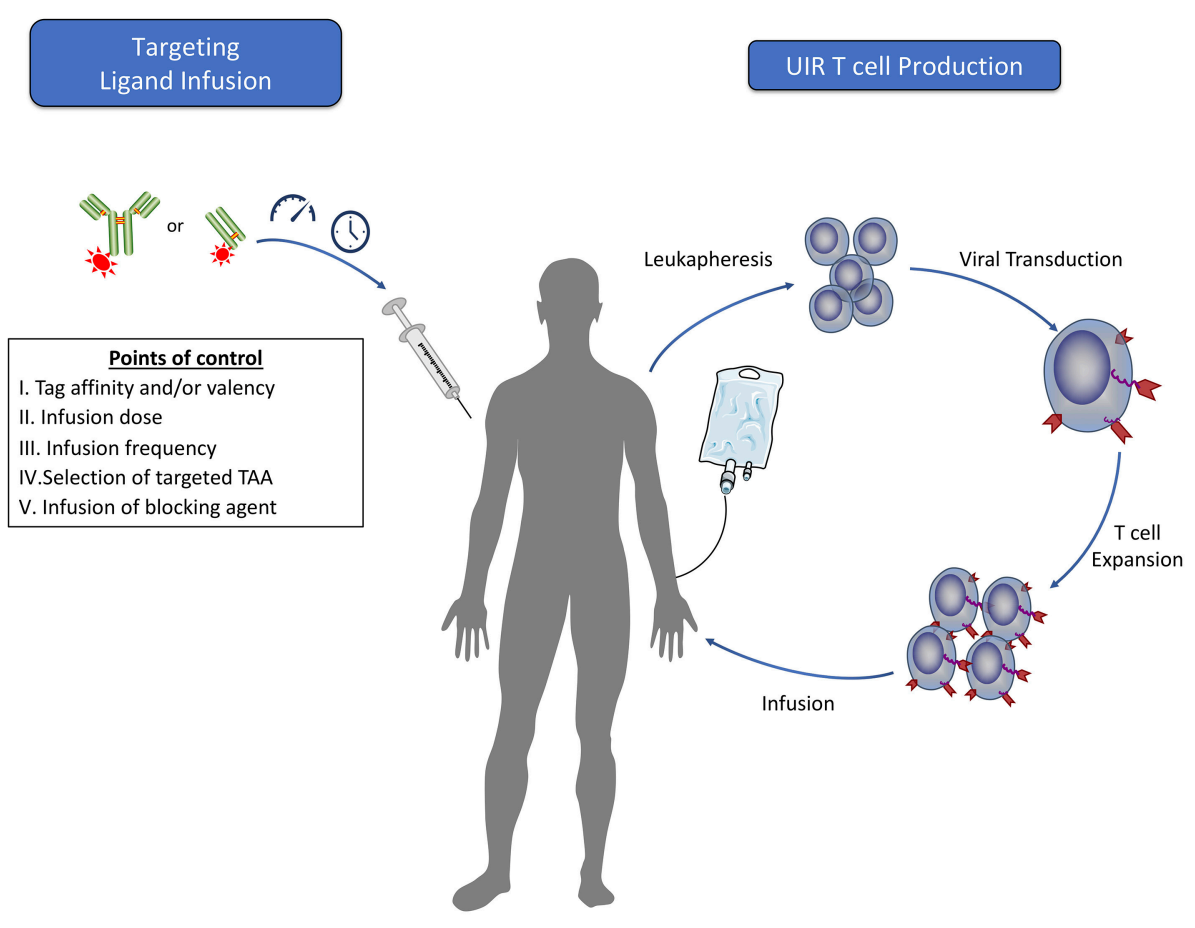

FIGURE 3 | Clinical steps for adoptive T cell therapy using universal immune receptors. The production of universal immune receptor T cells for clinical use would follow methods similar to those currently used for classical CAR T cells. Many of the potential benefits that a UIR system may confer would rely upon the dosing of targeting ligand into the patient. Prior to infusion, engineering of targeting ligands can be done independently of the receptor to maximize effector function against each target antigen. The ability to alter targeting ligand dose amounts and frequency would allow for tight regulation of T cell effector function and serve as a way to control T cell function to mitigate potential toxicity while achieving cancer regression. In the case of acute toxicity, infusion of a blocking agent may provide rapid cessation of $\mathrm{T}$ cell effector function. Furthermore, infusion of targeting ligands against multiple tumor antigens could offer the added benefit of targeting a heterogeneous cell population in the tumor with a single $T$ cell product.

infusion of CART19 cells results in a dramatic inflammatory process associated with supraphysiological $\mathrm{T}$ cell proliferation and significant cytokine elevations and is often associated with burden of disease. Since dose titration of TL allows for controllable cytokine secretion by UIR T cells in vitro and in vivo (45), a reduction in single TL dosing, the application of metronomic dosing or the use of an escalating TL dosing regimen would be anticipated to reduce the incidence or severity of CRS in the clinic. In a Nalm-6 model of UIR T cell treated leukemia, low dose administration of a CD19-specific TL induced low serum cytokine levels while triggering tumor clearance that was markedly slower than, but ultimately as effective as, that achieved with conventional CART19 cells (45). In some mice treated with UIR T cells, the Nalm-6 tumor later relapsed, at which time these mice were retreated with a higher dose of the TL, resulting in a secondary antitumor response that was similar to CART19 cells. This establishes the principle that UIR $\mathrm{T}$ cells can be administered in combination with an initially low but escalating TL doses to restrain CRS yet still achieve potent antitumor activity that is comparable to conventional CART19 cells.

In addition to CRS, patients receiving CD19-targeted Tcell therapy have prolonged B cell aplasia. Although this is a manageable toxicity it requires the need for potentially life long intravenous IgG (IV/IG) "replacement dosing" and antibiotics as a supplement (19). As demonstrated using a UIR syngeneic CD19+ leukemia model, cessation of anti-CD19 TL dosing after tumor clearance allows for the reestablishment of the endogenous B cell population, even in the continued presence of inactive UIR $\mathrm{T}$ cells, and is therefore an important step toward improving the quality of life for patients post-treatment (44).

Beyond TL dosing regimens, altering the affinity between the UIR and its cognate tag, or the affinity between the TL and the target antigen, are also feasible methods for enhanced control of the induced level of $\mathrm{T}$ cell effector function $(35,54)$. In the SUPRA CAR system, which relies upon synthetic leucine zipper pairing between the UIR and TL, affinity regulated function was demonstrated both in vitro and in vivo through alteration of the leucine zipper pairing affinity (54). This ability to control the affinity of TLs within a UIR system may provide an additional layer of safety, analogous to the use of lower affinity scFvs in CARs to provide specific targeting of tumor cells that express high levels of antigen, but not normal tissue expressing low level antigen $(90,91)$.

In a similar fashion, the valence of tags per TL molecule also impacts the efficacy of UIR $T$ cells. In one example, CD19 and CD22 Fabs with bivalent, site-specific placement of FITC consistently show greater potency in vitro and in vivo, 
compared to monovalent forms (44). However, the impact of tag valence has not been observed across all UIRs. The PNE system showed mixed results of TL potency when comparing site-specific monovalent vs. bivalent tag placement. Treatment of Nalm-6 xenografts with anti-CD19 Fabs and PNE CAR T cells showed equivalent efficacy between mono- and bivalent TLs, with a minor increase in $\mathrm{T}$ cell expansion seen in the monovalent group (45). It was also noted that optimal tag valency may be impacted by the selected hinge region of the UIR, since shorter hinge domains may sterically limit the ability of two independent UIR receptors to bind a single multivalent TL.

As a more direct means of T cell control, UIR T cell effector function can also be halted through the specific, timed blockade of the UIR-TL interaction using specific UIR or tag binding competitors $(40,54)$ (Figure 3 ). This method may be more rapid in effectiveness than withdrawal of targeting agent alone, which would depend upon the in vivo clearance kinetics of the TL to halt $\mathrm{T}$ cell function. In vivo studies with both the anti-FITC UIR and SUPRA CAR systems have shown that administration of an inert non-targeting agent containing the necessary UIR binding moiety in excess is a safe and effective method of inhibiting both cytokine secretion and tumor clearance $(40,54)$. This again has the added benefit of allowing the UIR T cells to persist in an inactive form after the delivery of blockade therapy, compared to suicide switch systems which result in T cell deletion and thus termination of the therapy.

\section{FLEXIBLE ANTIGEN TARGETING}

Translating the success of CAR $\mathrm{T}$ cell therapy achieved in hematological malignancies to the treatment of solid tumors has been largely unsuccessful but remains a significant clinical opportunity (2). One key factor for these unfavorable results is that solid tumors tend to have heterogeneous cell composition and therefore lack ubiquitous expression of a single tumor associated antigen (TAA) (32). Even when responses appear initially complete, antigen loss is another major challenge which CAR T cell therapy must overcome.

In clinical CART19 trials, tumor cell evasion can occur through the loss of antigen expression or the emergence of CD19 splice variants that lack the target epitope $(26,28,92)$. By virtue of their design, CAR-T cells target only a single tumor antigen. Although a second epitope could theoretically be targeted using a second infusion of CAR T cells, this would require expensive and time-consuming production of a new $\mathrm{T}$ cell product for each patient. Use of dual targeting CARs (93-95), T cell products containing two distinct CAR populations (31), or CAR T cells transduced to express two independent receptors (96) are all feasible approaches to overcome this hurdle, but these methods still restrict the total number of targetable antigens and do not address potential toxicity issues.

One of the main benefits of UIRs is their ability to target multiple antigens either sequentially or simultaneously (52) (Figure 1). Simultaneous targeting may alleviate the risk of antigen escape variants during treatment, while sequential targeting would allow for the use of the same engineered $\mathrm{T}$ cell to be redirected against additional antigens that arise as the tumor evolves through infusion of new TLs. Biopsy and proteomic characterization of a patient's relapsed/refractory tumor could also inform the tailored dosing of a sequential TL(s) at later treatment time points, a property unique to UIR platforms (49). An array of various solid and hematologic target antigens have already been successfully targeted by current UIR platforms in preclinical models, showing the expanded lytic potential that these systems have $(34,35,42,43,45,52,54)$. Urbanska et al. demonstrated that the same UIR $\mathrm{T}$ cell product could be readily used to target either mesothelin, FR $\alpha$ or EpCAM (52). A study by Cartellieri et al, also demonstrated that the use of two monospecific TLs or a single bispecific TL led to efficient redirected $\mathrm{T}$ cell activity against CD33 + CD123 + AML cells (46). Interestingly, the bispecific TL had enhanced anti-tumor efficacy when compared to the addition of its two individual monospecific subparts.

Beyond targeting multiple antigens on the cancer cell surface, simultaneous targeting of both tumor and non-tumor antigens has the potential to further enhance therapeutic effectiveness. Multiple studies have shown delayed tumor growth and increased $\mathrm{T}$ cell infiltration through targeting of antigens expressed on the tumor vasculature (97-99). Synergistic effects were observed with the combined targeting of tumor vasculature antigen VEGF receptor-2 and multiple tumor specific antigens (99). Similarly, targeting normal but tumor-promoting stromal cells using CAR $\mathrm{T}$ cells specific for fibroblast activating protein can inhibit tumor progression (100). Targeting of immunosuppressive cells in the tumor microenvironment, such as M2-like macrophages, may also enhance $\mathrm{T}$ cell function (101). While these are yet untested approaches, the potential to combine targeting of tumor and nontumor antigens with a single cell product could provide synergy and benefit to overall efficacy of treatment, and would be an approach unique to UIR T cells.

\section{MANIPULATING T CELL MEMORY, DIFFERENTIATION, AND INDIVIDUAL SUBSETS}

Most current clinical grade CAR $\mathrm{T}$ cell products are made from a patient's polyclonal $\mathrm{T}$ cell product without additional sorting for $\mathrm{T}$ cell subpopulations. It is well documented that certain $\mathrm{T}$ cell subtypes, such as naive and central memory $\mathrm{T}$ cells, have enhanced proliferation and persistence (102), and may therefore represent better starter cell subsets for use in engineered $\mathrm{T}$ cell therapy. Indeed, increased frequencies of $\mathrm{CD} 4+$ and central memory $\mathrm{T}$ cells in the pre-infusion product correlates with enhanced $\mathrm{T}$ cell persistence post-infusion, and the development and maintenance of CAR T cells that skew toward a central memory phenotype is associated with increased efficacy in patients on various CAR trials, including in B-ALL patients with sustained remissions $(7,9,103,104)$. Thus, identifying approaches that promote these favorable $\mathrm{T}$ cell properties is likely to improve clinical efficacy of the UIR approach. In this line of study, Rodgers et al. found that TL dosing can impact UIR $\mathrm{T}$ cell differentiation (45). Here the ability to titrate the 
effector activity of PNE-specific UIR T cells was shown to impact the post-infusion differentiation of the $\mathrm{T}$ cells in vivo using immunodeficient mouse models. Specifically, a lower dose of a CD19 targeting TL achieved the highest frequencies of CD4 and CD8 T cells with a CD45RA-CD62L+ central memory phenotype and a lower frequency of terminal effector cells in comparison to the high dose TL condition or to standard CART19 cells.

More recently, Viaud and colleagues used a murine form of the PNE-specific UIR system to examine the impact of the TL dose schedule on the formation of UIR $\mathrm{T}$ cell memory in a syngeneic mouse model of CD19 targeted therapy (51). In the immunocompetent syngeneic model, CD19+ B cell reconstitution after CD19 targeted therapy provides a potential depot for chronic antigen stimulation. The investigators found that both the timing and dosage of the administered CD19-specific TL regulated the amplitude and the phenotypic distribution of UIR T cell expansion. Notably, acute introductory TL dosing followed by a 3 week "rest" and a subsequent acute second TL cycle precipitated a dramatic T cell expansion after the second TL cycle, while longer TL dosing cycles with a reduction in the rest period stymied $\mathrm{T}$ cell expansion. The benefits of acute TL dosing and a rest phase was observed at both high and low TL dose concentrations. At the point of robust $\mathrm{T}$ cell expansion, TL expanded $\mathrm{T}$ cells predominantly displayed a CD8 effector and effector memory phenotype. Following $\mathrm{T}$ cell contraction, however, there was a relative reduction of these effector subtypes and a parallel retention of long-lived central memory cells, even in the absence of continued TL dosing. These findings demonstrate that the rest phase between TL dosing cycles is vital to both UIR $\mathrm{T}$ cell expansion and the formation of $\mathrm{T}$ cell central memory, and that the duration of the rest phase between TL cycles is more important than the TL dosing concentration.

While many UIRs function through a single tag binding domain, Cho et al. developed orthogonal UIRs which function through the binding of specific leucine zipper proteins on the receptor and TL (54). Since distinct pairs of leucine zippers have exclusive interactions with one another, they can be used to expand control of $\mathrm{T}$ cell function through split signaling domains and/or activation of specific $\mathrm{T}$ cell subsets. The use of split signaling domain CARs was developed to enhance safety, necessitating the need for dual antigen recognition by a first generation CAR and a chimeric costimulatory receptor (CCR) to elicit and focus robust effector function against tumor cells $(105,106)$. Split signaling functionality in a UIR system would allow for even tighter "AND" gate control of T cell function, with the added ability to independently dose-titrate the activity of each split receptor and modulation of targeted antigens with a single cell product (54). Control of individual $\mathrm{T}$ cell subsets is also achievable with orthogonal UIRs, allowing for incorporation of unique signaling domains into distinct cell subtypes and external control of signaling pathways through administration of specific TLs. With further development these logic gating UIRs have the capability of expanding the level of precision and tuning of immune functionality in $\mathrm{T}$ cell therapy.

\section{POTENTIAL ISSUES AND CHALLENGES FOR UIRS}

Though there are many benefits to developing UIR platforms for clinical use, they come with their own unique set of potential challenges. At the forefront is the potential for immunogenicity. Immunogenicity in CAR $\mathrm{T}$ cell treatment has been documented previously, most commonly in the development of human antimouse IgG antibodies (HAMAs) in response to murine derived scFvs (86). One instance of HAMA induction led to anaphylaxis and cardiac arrest in a patient receiving multiple and delayed infusion of an anti-mesothelin CAR bearing a murine derived scFv (107). Most UIR systems at present rely on the use of molecules that may elicit a similar immune response in patients. Though some UIR platforms claim to have low likelihood for immunogenicity $(41,42,45,46,48)$, careful clinical evaluation will be required for each UIR, especially those that uses nonendogenous proteins in their design.

The selection of optimally designed TLs also comes with its own unique challenges. To date, the CD16VV UIR is the only current platform to use unmanipulated clinical grade reagents as TLs. Other platforms, such as the FITC UIR, have used clinical grade reagents such as trastuzumab and cetuximab randomly conjugated with FITC molecules (40). Though these reagents were functional in vitro and in vivo, the addition of randomly conjugated molecules may lead to batch variation during TL production. The use of novel site-specific conjugation methods could mitigate this issue and allow for more consistent TL production using clinical reagents. All other platforms rely on the use of clinically untested TLs. Each system might then have to demonstrate clinical safety of the TL independently of the UIR T cells, which could come at a significant cost. Furthermore, the clear importance of tag placement on UIR effector function may necessitate the development of TLs genetically engineered to either contain the tag itself or contain introduced conjugation sites that subsequently allow for site-specific tag conjugation. This eliminates the use of clinically validated reagents and may further increase cost on TL production.

$\mathrm{T}$ cell expansion and persistence may be another issue with UIR T cells, as these two factors are key correlatives for predicting durable clinical remission $(10,24,108,109)$. Establishment of long-lived CART19 cells has been observed in patients years after initial infusion (11). Persistence of CAR T cells in the treatment of solid tumors has become a major point of focus in the field, though the reasons for poor persistence in solid tumor treatment are unclear and potentially multifactorial (110-112). Nevertheless, persistence of CAR T cells may be aided in part by continual antigen stimulation, as it is hypothesized that CART19 cells as a result of continual stimulation of the CAR $\mathrm{T}$ cells by reconstituting CD19+ B cells (9). While the ability to withdraw TL from UIR treatment might mitigate toxicities of CRS, neurotoxicity, and B cell aplasia, continual TL dosing and availability of antigen may be needed to induced $\mathrm{T}$ cell activation, expansion, and long term persistence. In preclinical models, UIR T cells have the capacity to persist in the absence of TL for several weeks, and can subsequently be reactivated 
with secondary TL dosing (45). The degree to which UIR T cell persistence is achievable in patients is not known, however optimization of TL dosing amount and frequency may be needed for each individual tumor antigen in order to achieve maximal $\mathrm{T}$ cell expansion and persistence.

$\mathrm{T}$ cell infiltration into solid tumors is associated with good clinical outcomes in some cancers (113). T cells can face difficulties penetrating the tumor stroma, accumulating around the periphery of the tumor mass or becoming excluded entirely (114). For UIR T cells, TLs will need to be able to penetrate and retain in the tumor to facilitate UIR engagement with tumor antigens. Akin to antibodies and their derivatives, TL penetrance will likely be impacted by multiple factors, including TL size, affinity for its cognate TAA, and biological half-life. A balance between molecular mass and binding affinity of TLs has a direct effect on tumor penetrance for both antibodies and $\mathrm{scFv}$ (115). As such, fine tuning these properties should be considered and may be necessary for each new TL being developed for antigen targeting.

Finally, one of the most unique aspects of UIRs is their ability to target multiple tumor antigens. In an ideal setting, simultaneous targeting of multiple antigens has the potential to broaden the initial antitumor response and mitigate antigen escape, while the ability to sequentially target multiple antigens could serve as a method to adapt $\mathrm{T}$ cell effector specificity and function to inter- and intratumoral changes that may occur over the course of treatment. Multi-antigen targeting functions only if multiple TAAs have been discovered and deemed safe, with cell lineage specific molecules such as CD19, CD20, CD22, and BCMA appearing to be the best druggable targets at present, although GD2 and EGFRvIII hold significant promise. Though much effort is being put into the discovery and testing of CAR $\mathrm{T}$ cells against new TAAs, it is a long and arduous process to discover a single safe and effective target (116). Though UIRs already provide several beneficial features over CAR T cells in the targeting of single TAAs, the full utility of UIRs will be reached when the cadre of TAAs is expanded.

\section{CONCLUSION}

Genetic engineering of T cells to target and eradicate tumors has been met with unprecedented clinical success in the treatment of hematologic malignancies. Recent FDA approval of CAR T cell therapies for the treatment of CD19+ malignancies has firmly established the use of adoptive $\mathrm{T}$ cell therapy as a viable clinical option for the treatment of disease. The identification of new target antigens coupled with improved CAR $\mathrm{T}$ cell design and manufacturing techniques are staged to overcome the hurdles that currently face expanding CAR $\mathrm{T}$ cell use across more cancer types.

\section{REFERENCES}

1. Gattinoni L, Powell DJ Jr, Rosenberg SA, Restifo NP. Adoptive immunotherapy for cancer: building on success. Nat Rev Immunol. (2006) 6:nri1842. doi: 10.1038/nri1842
Universal immune receptors are a part of this evolution, and offer the potential to improve upon many of the pitfalls that accompany CAR $\mathrm{T}$ cell therapy. The ability to target multiple antigens with a single, standardized immune receptor via the use of exogenous, inert targeting moieties represents an expanded approach to tumor eradication without the necessity to re-engineer or develop unique receptors for each target. Engineering of the immunological synapse is also possible without having to redesign the entire chimeric immune receptor itself, but rather through precision modifications to the TLs. Combined, these factors have the potential to greatly reduce manufacturing costs and increase development speed, especially in cases where multi-antigen targeting is beneficial to patient outcomes. UIRs also function to limit the risk of potentially fatal toxicities that may limit the expanded use of standard CAR T cells. The necessity for scheduled infusions of TL grants temporal and quantitative control over both $\mathrm{T}$ cell effector function and cytokine release. Pharmacokinetics and pharmacodynamics can be titrated in a more precise fashion than current achievable for conventional CAR T cells, thereby limiting the possibility of aberrant $\mathrm{T}$ cell activity without a means of control.

Finally, UIRs can be combined with other advancements in the field of adoptive $\mathrm{T}$ cell therapy to generate a true universal $\mathrm{T}$ cell product. Allogeneic CAR T cells lacking endogenous TCR and CD52 expression can evade detection and eradication by the unmatched recipient's immune system, resulting in a universal donor $\mathrm{T}$ cell product for potential widespread clinical use (117). Combining these universal T cells with a UIR creates the opportunity to significantly reduce the cost burden associated with the personalized medicine manufacturing approach of current CAR T cells. These cells could then be engineered with further enhancing elements to provide an optimized universal $\mathrm{T}$ cell therapy $(104,118,119)$.

Much work remains to be done in translating UIRs to the clinic, however progress in the field has occurred rapidly over the past few years with growing industry support. With continued pursuit of optimal UIR engineering, these receptors could one day represent the keystone around which the next generation of adoptive $T$ cell therapy is created.

\section{AUTHOR CONTRIBUTIONS}

NM and EH contributed to the literature review and drafting of the manuscript. DP contributed to the conception, drafting, and critical revision of the manuscript.

\section{ACKNOWLEDGMENTS}

The authors would like to acknowledge their grant funding support provided through the National Institute of Biomedical Imaging and Bioengineering, NIH (1R01EB026892-01).

2. June CH, O’Connor RS, Kawalekar OU, Ghassemi S, Milone MC. CAR $\mathrm{T}$ cell immunotherapy for human cancer. Science. (2018) 359:1361-5. doi: 10.1126/science.aar6711

3. Ribas A, Wolchok JD. Cancer immunotherapy using checkpoint blockade. Science. (2018) 359:1350-5. doi: 10.1126/science.aar4060 
4. Hoffman LM, Gore L. Blinatumomab, a bi-specific anti-CD19/CD3 BiTE ${ }^{\circledR}$ antibody for the treatment of acute lymphoblastic leukemia: perspectives and current pediatric applications. Front Oncol. (2014) 4:63. doi: $10.3389 /$ fonc. 2014.00063

5. Gill S, June $\mathrm{CH}$. Going viral: chimeric antigen receptor T-cell therapy for hematological malignancies. Immunol Rev. (2015) 263:68-89. doi: 10.1111/imr.12243

6. Porter DL, Levine BL, Kalos M, Bagg A, June CH. Chimeric antigen receptormodified T cells in chronic lymphoid leukemia. N Engl J Med. (2011) 365:725-33. doi: 10.1056/NEJMoa1103849

7. Kalos M, Levine BL, Porter DL, Katz S, Grupp SA, Bagg A, June CH. T cells with chimeric antigen receptors have potent antitumor effects and can establish memory in patients with advanced leukemia. Sci Transl Med. (2011) 3:95ra73. doi: 10.1126/scitranslmed.3002842

8. Grupp SA, Kalos M, Barrett D, Aplenc R, Porter DL, Rheingold SR, et al. Chimeric antigen receptor-modified T cells for acute lymphoid leukemia. $N$ Engl J Med. (2013) 368:1509-18. doi: 10.1056/NEJMoa1215134

9. Porter DL, Hwang W-T, Frey NV, Lacey SF, Shaw PA, Loren AW, et al. Chimeric antigen receptor $\mathrm{T}$ cells persist and induce sustained remissions in relapsed refractory chronic lymphocytic leukemia. Sci Transl Med. (2015) 7:303ra139. doi: 10.1126/scitranslmed.aac5415

10. Maude SL, Frey N, Shaw PA, Aplenc R, Barrett DM, Bunin NJ, et al. Chimeric antigen receptor T cells for sustained remissions in leukemia. $\mathrm{N} \mathrm{Engl} \mathrm{J} \mathrm{Med.}$ (2014) 371:1507-17. doi: 10.1056/nejmoa1407222

11. Schuster SJ, Svoboda J, Chong EA, Nasta SD, Mato AR, Anak Ö, et al. Chimeric antigen receptor T cells in refractory B-cell lymphomas. $N$ Engl J Med. (2017) 377:2545-54. doi: 10.1056/nejmoa1708566

12. Pehlivan KC, Duncan BB, Lee DW. CAR-T Cell Therapy for acute lymphoblastic leukemia: transforming the treatment of relapsed and refractory disease. Curr Hematol Malig Rep. (2018) 13:396-406. doi: 10.1007/s11899-018-0470-x

13. Locke FL, Neelapu SS, Bartlett NL, Siddiqi T, Chavez JC, Hosing CM, et al. Phase 1 results of ZUMA-1: a multicenter study of KTE-C19 anti-CD19 CAR T cell therapy in refractory aggressive lymphoma. Mol Ther. (2017) 25:285-95. doi: 10.1016/j.ymthe.2016.10.020

14. Ali S, Shi V, Maric I, Wang M, Stroncek D, Rose J, et al. T cells expressing an anti-B-cell maturation antigen chimeric antigen receptor cause remissions of multiple myeloma. Blood. (2016) 128:1688-700. doi: 10.1182/blood-2016-04-711903

15. Fry TJ, Shah NN, Orentas RJ, Stetler-Stevenson M, Yuan CM, Ramakrishna $\mathrm{S}$, et al. CD22-targeted CAR T cells induce remission in B-ALL that is naive or resistant to CD19-targeted CAR immunotherapy. Nat Med. (2017) 24:20. doi: $10.1038 / \mathrm{nm} .4441$

16. Zhang W, Wang Y, Guo Y, Dai H, Yang Q, Zhang Y, et al. Treatment of CD20-directed chimeric antigen receptor-modified $\mathrm{T}$ cells in patients with relapsed or refractory B-cell non-hodgkin lymphoma: an early phase IIa trial report. Signal Trans Target Ther. (2016) 1:sigtrans20162. doi: 10.1038/sigtrans.2016.2

17. Norelli M, Camisa B, Barbiera G, Falcone L, Purevdorj A, Genua M, et al. Monocyte-derived IL-1 and IL- 6 are differentially required for cytokinerelease syndrome and neurotoxicity due to CAR T cells. Nat Med. (2018) 24:739-48. doi: 10.1038/s41591-018-0036-4

18. Giavridis T, van der Stegen SJ, Eyquem J, Hamieh M, Piersigilli A, Sadelain M. CAR T cell-induced cytokine release syndrome is mediated by macrophages and abated by IL-1 blockade. Nat Med. (2018) 24:731-8. doi: 10.1038/s41591-018-0041-7

19. Davila ML, Sadelain M. Biology and clinical application of CAR $\mathrm{T}$ cells for $\mathrm{B}$ cell malignancies. Int $J$ Hematol. (2016) 104:6-17. doi: 10.1007/s12185-016-2039-6

20. Morgan RA, Yang JC, Kitano M, Dudley ME, Laurencot CM, Rosenberg SA. Case report of a serious adverse event following the administration of T Cells transduced with a chimeric antigen receptor recognizing ERBB2. Mol Ther. (2010) 18:843-51. doi: 10.1038/mt.2010.24

21. Lamers CH, Sleijfer S, van Steenbergen S, van Elzakker P, van Krimpen B, Groot C, et al. Treatment of metastatic renal cell carcinoma with CAIX CARengineered T cells: clinical evaluation and management of on-target toxicity. Mol Ther. (2013) 21:904-12. doi: 10.1038/mt.2013.17
22. Maude SL, Teachey DT, Rheingold SR, Shaw PA, Aplenc R, Barrett D, et al. Sustained remissions with CD19-specific chimeric antigen receptor (CAR)modified T cells in children with relapsed/refractory all. J Clin Oncol. (2016) 34:3011. doi: 10.1200/jco.2016.34.15_suppl.3011

23. Gardner R, Finney O, Smithers H, Leger KJ, Annesley CE, Summers C, et al. CD19CAR T cell products of defined CD4: CD8 composition and transgene expression show prolonged persistence and durable MRDnegative remission in pediatric and young adult B-cell ALL. Blood. (2016) 128:219. Available online at: http://www.bloodjournal.org/content/ $128 / 22 / 219$ ? sso- checked=true

24. Fraietta JA, Lacey SF, Orlando EJ, Pruteanu-Malinici I, Gohil M, Lundh S, et al. Determinants of response and resistance to CD19 chimeric antigen receptor (CAR) T cell therapy of chronic lymphocytic leukemia. Nat Med. (2018) 24:563-71. doi: 10.1038/s41591-018-0010-1

25. Bagashev A, Sotillo E, Wu G, Thomas-Tikhonenko A. The importance of CD19 exon 2 for Surface Localization: Closing the Ig-like Loop. Blood. (2015) 126:3433. Available online at: http://www.bloodjournal.org/content/ $126 / 23 / 3433$

26. Sotillo E, Barrett DM, Black KL, Bagashev A, Oldridge D, Wu G, et al. Convergence of acquired mutations and alternative splicing of CD19 enables resistance to CART-19 immunotherapy. Cancer Discovery. (2015) 5:1282-95. doi: 10.1158/2159-8290.cd-15-1020

27. Jacoby E, Nguyen SM, Fountaine TJ, Welp K, Gryder B, Qin H, et al. CD19 CAR immune pressure induces B-precursor acute lymphoblastic leukaemia lineage switch exposing inherent leukaemic plasticity. Nat Commun. (2016) 7:ncomms12320. doi: 10.1038/ncomms 12320

28. Gardner R, Wu D, Cherian S, Fang M, Hanafi L-A, Finney O, et al. Acquisition of a CD19-negative myeloid phenotype allows immune escape of MLL-rearranged B-ALL from CD19 CAR-T-cell therapy. Blood. (2016) 127:2406-10. doi: 10.1182/blood-2015-08-665547

29. Ruella M, Xu J, Barrett DM, Fraietta JA, Reich TJ, Ambrose DE, et al. Induction of resistance to chimeric antigen receptor $\mathrm{T}$ cell therapy by transduction of a single leukemic B cell. Nat Med. (2018) 24:1499-503. doi: 10.1038/s41591-018-0201-9

30. Gill S, Tasian SK, Ruella M, Shestova O, Li Y, Porter DL, et al. Preclinical targeting of human acute myeloid leukemia and myeloablation using chimeric antigen receptor-modified T cells. Blood. (2014) 123:2343-54. doi: 10.1182/blood-2013-09-529537

31. Ruella M, Barrett DM, Kenderian SS, Shestova O, Hofmann TJ, Perazzelli J, et al. Dual CD19 and CD123 targeting prevents antigen-loss relapses after CD19-directed immunotherapies. J Clin Invest. (2016) 126:3814-26. doi: $10.1172 /$ jci87366

32. Mirzaei HR, Rodriguez A, Shepphird J, Brown CE, Badie B. Chimeric antigen receptors $\mathrm{T}$ cell therapy in solid tumor: challenges and clinical applications. Front Immunol. (2017) 8:1850. doi: 10.3389/fimmu.2017.01850

33. O'Rourke DM, Nasrallah MP, Desai A, Melenhorst JJ, Mansfield K, Morrissette JJ, et al. A single dose of peripherally infused EGFRvIII-directed CAR $\mathrm{T}$ cells mediates antigen loss and induces adaptive resistance in patients with recurrent glioblastoma. Sci Transl Med. (2017) 9:eaaa0984. doi: $10.1126 /$ scitranslmed.aaa0984

34. Clémenceau B, Congy-Jolivet N, Gallot G, Vivien R, Gaschet J, Thibault G, et al. Antibody-dependent cellular cytotoxicity (ADCC) is mediated by genetically modified antigen-specific human T lymphocytes. Blood. (2006) 107:4669-77. doi: 10.1182/blood-2005-09-3775

35. Kudo K, Imai C, Lorenzini P, Kamiya T, Kono K, Davidoff AM, et al. T lymphocytes expressing a CD16 signaling receptor exert antibody-dependent cancer cell killing. Cancer Res. (2013) 74:93-103. doi: 10.1158/00085472.CAN-13-1365

36. Ochi F, Fujiwara H, Tanimoto K, Asai H, Miyazaki Y, Okamoto S, et al. Gene-modified human $\alpha / \beta-\mathrm{T}$ cells expressing a chimeric CD16$\mathrm{CD} 3 \zeta$ receptor as adoptively transferable effector cells for anticancer monoclonal antibody therapy. Cancer Immunol. (2014) 2:249-62. doi: 10.1158/2326-6066.cir-13-0099-t

37. D’Aloia M, Caratelli S, Palumbo C, Battella S, Arriga R, Lauro D, et al. $\mathrm{T}$ lymphocytes engineered to express a CD16-chimeric antigen receptor redirect T-cell immune responses against immunoglobulin G-opsonized target cells. Cytotherapy. (2016) 18:278-90. doi: 10.1016/j.jcyt.2015.10.014 
38. Urbanska K, Lynn RC, Stashwick C, Thakur A, Lum LG, Powell DJ. Targeted cancer immunotherapy via combination of designer bispecific antibody and novel gene-engineered T cells. J Transl Med. (2014) 12:347. doi: 10.1186/s12967-014-0347-2

39. Ambrose C, Su L, Wu L, Lobb RR, Rennert PD. Abstract 3768: CAR T cells specific for CD19 can be redirected to kill CD19 negative tumors. Cancer Res. (2017) 77:3768. doi: 10.1158/1538-7445.am2017-3768

40. Tamada K, Geng D, Sakoda Y, Bansal N, Srivastava R, Li Z, et al. Redirecting gene-modified t cells toward various cancer types using tagged antibodies. Clin Cancer Res. (2012) 18:6436-45. doi: 10.1158/1078-0432.CCR-12-1449

41. Bachmann D, Aliperta R, Bergmann R, Feldmann A, Koristka S, Arndt C, et al. Retargeting of UniCAR T cells with an in vivo synthesized target module directed against CD19 positive tumor cells. Oncotarget. (2014) 5:7487-500. doi: 10.18632/oncotarget.23556

42. Feldmann A, Arndt C, Bergmann R, Loff S, Cartellieri M, Bachmann D, et al. Retargeting of T lymphocytes to PSCA- or PSMA positive prostate cancer cells using the novel modular chimeric antigen receptor platform technology “UniCAR." Oncotarget. (2014) 8:31368-85. doi: 10.18632/oncotarget.15572

43. Kim M, Ma JS, Yun H, Cao Y, Kim J, Chi V, et al. Redirection of genetically engineered CAR-T cells using bifunctional small molecules. J Am Chem Soc. (2015) 137:2832-5. doi: 10.1021/jacs.5b00106

44. Ma JS, Kim JY, Kazane SA, Choi S-HH, Yun HY, Kim MS, et al. Versatile strategy for controlling the specificity and activity of engineered T cells. Proc Natl Acad Sci USA. (2016) 113:E450-8. doi: 10.1073/pnas.1524193113

45. Rodgers DT, Mazagova M, Hampton EN, Cao Y, Ramadoss NS, Hardy IR, et al. Switch-mediated activation and retargeting of CAR-T cells for B-cell malignancies. Proc Natl Acad Sci USA. (2016) 113: E459-68. doi: 10.1073/pnas.1524155113

46. Cartellieri M, Feldmann A, Koristka S, Arndt C, Loff S, Ehninger A, et al. Switching CAR T cells on and off: a novel modular platform for retargeting of T cells to AML blasts. Blood Cancer J. (2016) 6:e458. doi: 10.1038/bcj.2016.61

47. Cao Y, Rodgers DT, Du J, Ahmad I, Hampton EN, Ma JS, et al. Design of switchable chimeric antigen receptor $\mathrm{T}$ cells targeting breast cancer. Angewandte Chemie Int Ed. (2016) 55:7520-4. doi: 10.1002/anie.201601902

48. Albert S, Arndt C, Feldmann A, Bergmann R, Bachmann D, Koristka S, et al. A novel nanobody-based target module for retargeting of $\mathrm{T}$ lymphocytes to EGFR-expressing cancer cells via the modular UniCAR platform. OncoImmunology. (2017) 6:e1287246. doi: 10.1080/2162402x.2017.1287246

49. Raj D, Yang M-H, Rodgers D, Hampton EN, Begum J, Mustafa A, et al. Switchable CAR-T cells mediate remission in metastatic pancreatic ductal adenocarcinoma. Gut. (2018) 1-13. doi: 10.1136/gutjnl-2018-316595

50. Chu W, Zhou Y, Tang Q, Wang M, Ji Y, Yan J, et al. Bi-specific ligandcontrolled chimeric antigen receptor T-cell therapy for non-small cell lung cancer. Biosci Trends. (2018) 12:298-308. doi: 10.5582/bst.2018.01048

51. Viaud S, Ma JS, Hardy IR, Hampton EN, Benish B, Sherwood L, et al. Switchable control over in vivo CAR T expansion, B cell depletion, and induction of memory. Proc National Acad Sci. (2018) 115:E10898-906. doi: 10.1073/pnas.1810060115

52. Urbanska K, Lanitis E, Poussin M, Lynn RC, Gavin BP, Kelderman S, et al. A universal strategy for adoptive immunotherapy of cancer through use of a novel T-cell antigen receptor. Cancer Res. (2012) 72:1844-52. doi: 10.1158/0008-5472.can-11-3890

53. Lohmueller JJ, Ham JD, Kvorjak M, Finn OJ. mSA2 affinity-enhanced biotinbinding CAR T cells for universal tumor targeting. OncoImmunology. (2017) 7:e1368604. doi: 10.1080/2162402x.2017.1368604

54. Cho J, Collins JJ, Wong WW. Universal chimeric antigen receptors for multiplexed and logical control of T cell responses. Cell. (2018) 173:1426-38. doi: 10.1016/j.cell.2018.03.038

55. Koene H, Kleijer M, Algra J, Roos D, von dem Borne A, de Haas M. Fc gammaRIIIa-158V/F polymorphism influences the binding of IgG by natural killer cell Fc gammaRIIIa, independently of the Fc gammaRIIIa-48L/R/H phenotype. Blood. (1997) 90:1109-14.

56. Clémenceau B, Valsesia-Wittmann S, Jallas A-C, Vivien R, Rousseau R, Marabelle A, et al. In vitro and in vivo comparison of lymphocytes transduced with a human CD16 or with a chimeric antigen receptor reveals potential offtarget interactions due to the IgG2 CH2-CH3 CAR-spacer. I Immunol Res. (2015) 2015:482089. doi: 10.1155/2015/482089
57. Finney H, Lawson A, Bebbington C, Weir A. Chimeric receptors providing both primary and costimulatory signaling in $\mathrm{T}$ cells from a single gene product. J Immunol. (1998) 161:2791-7.

58. Carpenito C, Milone MC, Hassan R, Simonet JC, Lakhal M, hoski M, et al. Control of large, established tumor xenografts with genetically retargeted human T cells containing CD28 and CD137 domains. Proc Natl Acad Sci. (2009) 106:3360-5. doi: 10.1073/pnas.0813101106

59. Song D-G, Ye Q, Poussin M, Harms GM, Figini M, Powell DJ. CD27 costimulation augments the survival and antitumor activity of redirected human $\mathrm{T}$ cells in vivo. Blood. (2012) 119:696-706. doi: 10.1182/blood-2011-03-344275

60. Zhao Z, Condomines M, van der Stegen S, Perna F, Kloss CC, Gunset G, et al. Structural design of engineered costimulation determines tumor rejection kinetics and persistence of CAR T cells. Cancer Cell. (2015) 28:415-28. doi: 10.1016/j.ccell.2015.09.004

61. Long AH, Haso WM, Shern JF, Wanhainen KM, Murgai M, Ingaramo $\mathrm{M}$, et al. 4-1BB costimulation ameliorates $\mathrm{T}$ cell exhaustion induced by tonic signaling of chimeric antigen receptors. Nat Med. (2015) 21:581-90. doi: $10.1038 / \mathrm{nm} .3838$

62. Hammill JA, VanSeggelen H, Helsen CW, Denisova GF, Evelegh C, Tantalo DG, et al. Designed ankyrin repeat proteins are effective targeting elements for chimeric antigen receptors. J Immu Cancer. (2015) 3:1-11. doi: 10.1186/s40425-015-0099-4

63. Ellebrecht CT, Bhoj VG, Nace A, Choi EJ, Mao X, Cho MJ, et al. Reengineering chimeric antigen receptor $\mathrm{T}$ cells for targeted therapy of autoimmune disease. Science. (2016) 353:179-84. doi: $10.1126 /$ science.aaf6756

64. Lee CM, Tannock IF. The distribution of the therapeutic monoclonal antibodies cetuximab and trastuzumab within solid tumors. BMC Cancer. (2010) 10:1-11. doi: 10.1186/1471-2407-10-255

65. Rudnick SI, Adams GP. Affinity and avidity in antibody-based tumor targeting. Cancer Biother Amp Radiopharm. (2009) 24:155-61. doi: 10.1089/cbr.2009.0627

66. Chang ZL, Lorenzini MH, Chen X, Tran U, Bangayan NJ, Chen YY. Rewiring T-cell responses to soluble factors with chimeric antigen receptors. Nat Chem Biol. (2018) 14:317-24. doi: 10.1038/nchembio.2565

67. Bluemel C, Hausmann S, Fluhr P, skandarajah M, Stallcup WB, Baeuerle $\mathrm{PA}$, et al. Epitope distance to the target cell membrane and antigen size determine the potency of $\mathrm{T}$ cell-mediated lysis by BiTE antibodies specific for a large melanoma surface antigen. Cancer Immunol Immunother. (2010) 59:1197-209. doi: 10.1007/s00262-010-0844-y

68. Hudecek M, Lupo-Stanghellini M-T, Kosasih PL, Sommermeyer D, Jensen MC, Rader C, $t$ al. Receptor affinity and extracellular domain modifications affect tumor recognition by ROR1-specific chimeric antigen receptor T cells. Clin Cancer Res. (2013) 19:3153-64. doi: 10.1158/1078-0432.ccr-13-0330

69. Guest RD, Hawkins RE, Kirillova N, Cheadle EJ, Arnold J, O’Neill A, et al. The role of extracellular spacer regions in the optimal design of chimeric immune receptors: evaluation of four different scFvs and antigens. J Immunother. (2005) 28:203. doi: 10.1097/01.cji.0000161397.96582.59

70. Wilkie S, Picco G, Foster J, Davies DM, Julien S, Cooper L, et al. Retargeting of human $\mathrm{T}$ cells to tumor-associated MUC1: the evolution of a chimeric antigen receptor. J Immunol. (2008) 180:4901-9. doi: 10.4049/jimmunol.180.7.4901

71. Bonifant CL, Jackson HJ, Brentjens RJ, Curran KJ. Toxicity and management in CAR T-cell therapy. Mol Ther Oncolytics. (2016) 3:16011. doi: $10.1038 /$ mto.2016.11

72. D'Aloia M, Zizzari I, Sacchetti B, Pierelli L, Alimandi M. CAR-T cells: the long and winding road to solid tumors. Cell Death Dis. (2018) 9:282. doi: 10.1038/s41419-018-0278-6

73. Maude SL, Teachey DT, Porter DL, Grupp SA. CD19-targeted chimeric antigen receptor T-cell therapy for acute lymphoblastic leukemia. Blood. (2015) 125:4017-23. doi: 10.1182/blood-2014-12-580068

74. Gust J, Hay KA, Hanafi L-A, Li D, Myerson D, Gonzalez-Cuyar LF, et al. Endothelial activation and blood-brain barrier disruption in neurotoxicity after adoptive immunotherapy with CD19 CAR-T cells. Cancer Discovery. (2017) 7:1404-19. doi: 10.1158/2159-8290.cd17-0698 
75. Greco R, Oliveira G, Stanghellini M, Vago L, Bondanza A, Peccatori J, et al. Improving the safety of cell therapy with the TK-suicide gene. Front Pharmacol. (2015) 6:95. doi: 10.3389/fphar.2015.00095

76. Ciceri F, Bonini C, Marktel S, Zappone E, Servida P, Bernardi M, et al. Antitumor effects of HSV-TK-engineered donor lymphocytes after allogeneic stem-cell transplantation. Blood. (2007) 109:4698-707. doi: 10.1182/blood-2006-05-023416

77. Zhang E, Xu H. A new insight in chimeric antigen receptor-engineered $\mathrm{T}$ cells for cancer immunotherapy. J Hematol Oncol. (2017) 10:1. doi: 10.1186/s13045-016-0379-6

78. Stasi A, Tey S-K, Dotti G, Fujita Y, Kennedy-Nasser A, Martinez C, et al. Inducible Apoptosis as a Safety Switch for Adoptive Cell Therapy. New Engl J Medicine. (2011) 365:1673-83. doi: 10.1056/NEJMoa1106152

79. Zhou X, Dotti G, Krance RA, Martinez CA, Naik S, Kamble RT, et al. Inducible caspase-9 suicide gene controls adverse effects from alloreplete T cells after haploidentical stem cell transplantation. Blood. (2015) 125:4103-13. doi: 10.1182/blood-2015-02-628354

80. Gargett T, Brown MP. The inducible caspase- 9 suicide gene system as a "safety switch" to limit on-target, off-tumor toxicities of chimeric antigen receptor $\mathrm{T}$ cells. Front Pharmacol. (2014) 5:235. doi: 10.3389/fphar.2014.00235

81. Stavrou M, Philip B, Traynor-White C, Davis CG, Onuoha S, Cordoba S, et al. A rapamycin activated caspase 9 based suicide gene. Mol Ther. (2018) 26:1266-76. doi: 10.1016/j.ymthe.2018.03.001

82. Wang X, Chang W-C, Wong CW, Colcher D, Sherman M, Ostberg JR, et al. A transgene-encoded cell surface polypeptide for selection, in vivo tracking, and ablation of engineered cells. Blood. (2011) 118:1255-63. doi: 10.1182/blood-2011-02-337360

83. Koneru M, O’Cearbhaill R, Pendharkar S, Spriggs DR, Brentjens RJ. a phase I clinical trial of adoptive T cell therapy using IL-12 secreting MUC-16ecto directed chimeric antigen receptors for recurrent ovarian cancer. J Transl Med. (2015) 13:102. doi: 10.1186/s12967-015-0460-x

84. Philip B, Kokalaki E, Mekkaoui L, Thomas S, Straathof K, Flutter B, et al. A highly compact epitope-based marker/suicide gene for easier and safer T-cell therapy. Blood. (2014) 124:1277-87. doi: 10.1182/blood-2014-01545020

85. Marin V, Cribioli E, Philip B, Tettamanti S, Pizzitola I, Biondi A, et al. Comparison of different suicide-gene strategies for the safety improvement of genetically manipulated T cells. Hum Gene Ther Method. (2012) 23:376-86. doi: 10.1089/hgtb.2012.050

86. Beatty GL, Haas AR, Maus MV, Torigian DA, Soulen MC, Plesa G, et al. Mesothelin-specific chimeric antigen receptor mRNA-engineered $\mathrm{T}$ cells induce antitumor activity in solid malignancies. Cancer Immunol Res. (2014) 2:112-20. doi: 10.1158/2326-6066.CIR-13-0170

87. Fedorov VD, Themeli M, Sadelain M. PD-1- and CTLA-4-Based inhibitory chimeric antigen receptors (iCARs) divert off-target immunotherapy responses. Sci Transl Med. (2013) 5:215ra172. doi: 10.1126/scitranslmed.3006597

88. Han X, Bryson PD, Zhao Y, Cinay GE, Li S, Guo Y, t al. Masked chimeric antigen receptor for tumor-specific activation. Mol Ther. (2017) 25:274-84. doi: 10.1016/j.ymthe.2016.10.011

89. Maude SL, Barrett D, Teachey DT, Grupp SA. Managing cytokine release syndrome associated with novel T cell-engaging therapies. Cancer J. (2014) 20:119. doi: 10.1097/PPO.0000000000000035

90. Liu X, Jiang S, Fang C, Yang S, Olalere D, Pequignot EC, et al. Affinitytuned ErbB2 or EGFR chimeric antigen receptor T cells exhibit an increased therapeutic index against tumors in mice. Cancer Res. (2015) 75:3596-607. doi: 10.1158/0008-5472.can-15-0159

91. Song D-G, Ye Q, Poussin M, Liu L, Figini M, Jr. DJ. A fully human chimeric antigen receptor with potent activity against cancer cells but reduced risk for off-tumor toxicity. Oncotarget. (2015) 6:21533-46. doi: 10.18632/oncotarget.4071

92. Vyas M, Müller R, von Strandmann E. Antigen loss variants: catching hold of escaping foes. Front Immunol. (2017) 8:175. doi: 10.3389/fimmu.2017.00175

93. Grada Z, Hegde M, Byrd T, Shaffer DR, Ghazi A, Brawley VS, et al. TanCAR: a novel bispecific chimeric antigen receptor for cancer immunotherapy. Mol Ther Nucleic Acids. (2013) 2:e105. doi: 10.1038/mtna. 2013.32
94. Hegde M, Mukherjee M, Grada Z, Pignata A, Landi D, Navai SA, et al. Tandem CAR T cells targeting HER2 and IL13R $\alpha 2$ mitigate tumor antigen escape. J Clin Invest. (2016) 126:3036-52. doi: 10.1172/jci83416

95. Schneider D, Xiong Y, Wu D, N?lle V, Schmitz S, Haso W, et al. A tandem CD19/CD20 CAR lentiviral vector drives on-target and off-target antigen modulation in leukemia cell lines. J Immunother Cancer. (2017) 5:42. doi: 10.1186/s40425-017-0246-1

96. Pong C, Westwood JA, Berry LJ, Darcy PK, Kershaw MH. Enhancing the specificity of T-cell cultures for adoptive immunotherapy of cancer. Immunotherapy. (2011) 3:33-48. doi: 10.2217/imt.10.81

97. Santoro S, Kim S, Motz G, Alatzoglou D, Li C, Irving M, et al. T Cells bearing a chimeric antigen receptor against prostate-specific membrane antigen mediate vascular disruption and result in tumor regression. Cancer Immunol Res. (2014) 3:68-84. doi: 10.1158/2326-6066.CIR-14-0192

98. Lanitis E, Irving M, Coukos G. Targeting the tumor vasculature to enhance $\mathrm{T}$ cell activity. Curr Opin Immunol. (2015) 33:55-63. doi: 10.1016/j.coi.2015.01.011

99. Chinnasamy D, Tran E, Yu Z, Morgan RA, Restifo NP, Rosenberg SA. Simultaneous targeting of tumor antigens and the tumor vasculature using T lymphocyte transfer synergize to induce regression of established tumors in mice. Cancer Res. (2013) 73:3371-80. doi: 10.1158/0008-5472.can-12-3913

100. Wang L-CS, Lo A, Scholler J, Sun J, Majumdar RS, Kapoor V, et al. Targeting fibroblast activation protein in tumor stroma with chimeric antigen receptor $\mathrm{T}$ cells can inhibit tumor growth and augment host immunity without severe toxicity. Cancer Immunol Res. (2014) 2:154-66. doi: 10.1158/2326-6066.cir-13-0027

101. Lynn RC, Poussin M, Kalota A, Feng Y, Low PS, Dimitrov DS, et al. Targeting of folate receptor $\beta$ on acute myeloid leukemia blasts with chimeric antigen receptor-expressing T cells. Blood. (2015) 125:3466-76. doi: 10.1182/blood-2014-11-612721

102. Golubovskaya $\mathrm{V}, \mathrm{Wu}$ L. Different subsets of $\mathrm{T}$ cells, memory, effector functions, and CAR-T immunotherapy. Cancers. (2016) 8:36. doi: 10.3390/cancers8030036

103. Louis C, Savoldo B, Dotti G, Pule M, Yvon E. Antitumor activity and long-term fate of chimeric antigen receptor-positive $\mathrm{T}$ cells in patients with neuroblastoma. Blood. (2011) 118:6050-6. doi: 10.1182/blood-2011-05-354449

104. Fraietta JA, Nobles CL, Sammons MA, Lundh S, Carty SA, Reich TJ, et al. Disruption of TET2 promotes the therapeutic efficacy of CD19-targeted T cells. Nature. (2018) 558:307-12. doi: 10.1038/s41586-018-0178-z

105. Lanitis E, Poussin M, Klattenhoff AW, Song D, Sandaltzopoulos R, June CH, et al. Chimeric antigen receptor $\mathrm{T}$ cells with dissociated signaling domains exhibit focused antitumor activity with reduced potential for toxicity in vivo. Cancer Immunol Res. (2013) 1:43-53. doi: 10.1158/2326-6066.CIR-13-0008

106. Kloss CC, Condomines M, Cartellieri M, Bachmann M, Sadelain M. Combinatorial antigen recognition with balanced signaling promotes selective tumor eradication by engineered T cells. Nat Biotechnol. (2013) 31:71. doi: $10.1038 /$ nbt.2459

107. Maus MV, Haas AR, Beatty GL, Albelda SM, Levine BL, Liu X, et al. T cells expressing chimeric antigen receptors can cause anaphylaxis in humans. Cancer immunol Res. (2013) 1:26-31. doi: 10.1158/2326-6066.cir-13-0006

108. Robbins PF, Dudley ME, Wunderlich J, El-Gamil M, Li YF, Zhou J, et al. Cutting edge: persistence of transferred lymphocyte clonotypes correlates with cancer regression in patients receiving cell transfer therapy. J Immunol. (2004) 173:7125-30. doi: 10.4049/jimmunol.173.12.7125

109. Mueller KT, Waldron ER, Grupp SA, Levine JE, Laetsch TW, Pulsipher MA, et al. Clinical pharmacology of tisagenlecleucel in BCell acute lymphoblastic leukemia. Clin Cancer Res. (2018) 24:6175-84. doi: 10.1158/1078-0432.ccr-18-0758

110. Thistlethwaite FC, Gilham DE, Guest RD, Rothwell DG, Pillai M, Burt DJ, et al. The clinical efficacy of first-generation carcinoembryonic antigen (CEACAM5)-specific CAR $\mathrm{T}$ cells is limited by poor persistence and transient pre-conditioning-dependent respiratory toxicity. Cancer Immunol. Immunother. (2017) 66:1425-36. doi: 10.1007/s00262-017-2034-7

111. Kershaw MH, Westwood JA, Parker LL, Wang G, Eshhar Z, Mavroukakis $\mathrm{SA}$, et al. A phase I study on adoptive immunotherapy using genemodified T cells for ovarian cancer. Clin Cancer Res. (2006) 12:6106-15. doi: 10.1158/1078-0432.CCR-06-1183 
112. Hege KM, Bergsland EK, Fisher GA, Nemunaitis JJ, Warren RS, McArthur JG, et al. Safety, tumor trafficking and immunogenicity of chimeric antigen receptor (CAR)-T cells specific for TAG-72 in colorectal cancer. J Immu Cancer. (2017) 5:22. doi: 10.1186/s40425-017-0222-9

113. Melero I, Rouzaut A, Motz GT, Coukos G. T-Cell and NKCell Infiltration into solid tumors: a key limiting factor for efficacious cancer immunotherapy. Cancer Discovery. (2014)522-6. doi: 10.1158/2159-8290.CD-13-0985

114. Lanitis E, Dangaj D, Irving M, Coukos G. Mechanisms regulating Tcell infiltration and activity in solid tumors. Ann Oncol. (2017) 28(suppl, 12):xii18-32 doi: 10.1093/annonc/mdx238

115. Xenaki KT, Oliveira S, van en Henegouwen PM. Antibody or antibody fragments: implications for molecular imaging and targeted therapy of solid tumors. Front Immunol. (2017) 8:1287. doi: 10.3389/fimmu.2017.01287

116. Dotti G, Gottschalk S, Savoldo B, Brenner MK. Design and development of therapies using chimeric antigen receptor-expressing $\mathrm{T}$ cells. Immunol Reviews. (2014) 257:107-26. doi: 10.1111/imr.12131

117. Qasim W, Zhan H, Samarasinghe S, Adams S, Amrolia P, Stafford S, et al. Molecular remission of infant B-ALL after infusion of universal TALEN gene-edited CAR T cells. Sci Transl Med. (2017) 9:eaaj2013. doi: 10.1126/scitranslmed.aaj2013
118. Kloss CC, Lee J, Zhang A, Chen F, Melenhorst J, Lacey SF, et al. Dominant negative TGF $\beta$ receptor enhances PSMA targeted human CAR $\mathrm{T}$ cell proliferation and augments tumor eradication in prostate cancer. Mol Ther. (2018) 26:1855-66. doi: 10.1016/j.ymthe.2018. 05.003

119. Liu X, Ranganathan R, Jiang S, Fang C, Sun J, Kim S, et al. A chimeric switch-receptor targeting PD1 augments the efficacy of second-generation CAR T cells in advanced solid tumors. Cancer Res. (2016) 76:1578-90. doi: 10.1158/0008-5472.can-15-2524

Conflict of Interest Statement: The authors declare that the research was conducted in the absence of any commercial or financial relationships that could be construed as a potential conflict of interest.

Copyright $\odot 2019$ Minutolo, Hollander and Powell. This is an open-access article distributed under the terms of the Creative Commons Attribution License (CC BY). The use, distribution or reproduction in other forums is permitted, provided the original author(s) and the copyright owner(s) are credited and that the original publication in this journal is cited, in accordance with accepted academic practice. No use, distribution or reproduction is permitted which does not comply with these terms. 